\title{
A ALTERIDADE E A IDENTIDADE RIZOMA ${ }^{1}$
}

\section{THE OTHERNESS AND THE RHIZOME IDENTITY}

\author{
MENDES, Sávio Damato \\ DIAS PIRES, André Monteiro Guimarães
}

\begin{abstract}
RESUMO: Este trabalho busca efetuar uma reflexão sobre a diversidade e identidade cultural na pluralidade imaginativa ativa expressa nos diversos repositórios simbólicos, artísticos, religiosos, sociais, econômicos, linguísticos, dentre outros, que nos cercam. O contato e mútua interferência entre os povos forçam-nos, atualmente, a rever os conceitos de cultura e de identidades em termos planetários sob o ângulo da dispersão rizomática e não mais sob a ótica estreita de uma visão de mundo com raiz única e universal. Nesse contexto, é a diversidade que passa a ser valorizada. Entretanto, como reconhecer e valorizar essa teia rizomática de relações sem desvalorizar o individual? É o que buscaremos demonstrar a seguir.
\end{abstract}

PALAVRAS-CHAVE: Diversidade, identidade, individualidade, rizoma, crioulização.

\begin{abstract}
This work seeks to reflect on diversity and cultural identity in the active imaginative plurality expressed in the various symbolic, artistic, religious, social, economic, linguistic, and other repositories that surround us. Contact and mutual interference between peoples force us today to revise the concepts of culture and identities in planetary terms under the rhizomatic scattering angle and no longer under the narrow view of a world view with a single universal root. In this context, it is the diversity that comes to be valued. However, how to recognize and value this rhizomatic web of relationships without devaluing the individual? This is what we will try to demonstrate next.
\end{abstract}

KEYWORDS: Diversity, identity, individuality, rhizome, creolization.

A morte de cada homem diminui-me, pois faço parte da humanidade; eis porque nunca me pergunto por quem dobram os sinos: é por mim. John Donne

\footnotetext{
${ }^{1}$ Artigo desenvolvido com o apoio da FAPEMIG, por meio de bolsa de Doutorado concedida a um dos autores.
} 
A epígrafe escolhida para abrir os pensamentos deste estudo chama a atenção por sintetizar toda a teia de reflexões que se pretende construir aqui: a importância de cada indivíduo como ponto singular que forma o rizoma ${ }^{2}$ da diversidade/identidade, ou, como chama o pensador francês Édouard Glissant, a “identidade rizoma”. Deparei-me com essa citação de John Donne, há poucos anos, em um artigo de Leonardo Boff sobre o atentado contra a revista francesa Charlie Hebdo, ocorrido em 7 de janeiro de 2015, intitulado "Eu não sou Charlie, je ne suis pas Charlie".

Essa trilha da referência é aqui apresentada com o duplo objetivo de referenciar, em seu sentido mais amplo, e apontar os primeiros fios que, desdobrados, nos permitirão refletir sobre a dinâmica de interação dos indivíduos e das culturas a se afetarem, tanto no que se refere aos diversos processos migratórios, processo descrito por Glissant como crioulização ${ }^{3}$, como também no estabelecimento das possibilidades de pensar a importância das existências individuais como vetores para o estabelecimento de novas e imprevisíveis variáveis no conjunto das identidades globais.

Tais existências individuais serão consideradas, em determinados momentos deste estudo, de forma virtual, alegórica, como pontos em uma rede sistêmica, como veremos, oscilando entre a tendência para a ruptura e a preservação do sistema através de sua macro estrutura, que será visualizada como uma teia rizomática dinâmica, caracterizadora simbólica das relações entre as diversas culturas no globo hoje.

Pensar na diversidade e identidade cultural é pensar também na pluralidade imaginativa ativa expressa nos diversos repositórios simbólicos, artísticos, religiosos, sociais, econômicos, linguísticos, dentre outros, que nos cercam a todos. Como diz Glissant (...) "falo e sobretudo escrevo na presença de todas as línguas do mundo" (2011, p. 43). Todas as línguas e todas as culturas encontram-se, de uma forma ou de outra, conectadas.

Assim, pensar as relações entre as culturas como multiconectadas impõe-nos, ainda no rastro de Glissant, um esforço imaginativo e conceitual extra, uma vez que essas relações colocam-nos frente à necessidade de repensar as dinâmicas de forças que formam os referenciais de identidade: "as humanidades de hoje estão abandonando dificilmente algo em

\footnotetext{
2 Utilizamos a palavra "rizoma" e suas variações como um conceito sinônimo a diversidade, seguindo o pensamento de Deleuze que opõe as estruturas de pensamento de raiz única, que buscam um único caminho, ao sistema rizomático, formado pela multiplicidade: "Uma das características mais importantes do rizoma talvez seja a de ter sempre múltiplas entradas" (DELEUZE, 2011, p.30). Talvez o mais ilustrativo exemplo de sistema rizomático na natureza seja a estrutura que se formam em um jardim ou campo coberto por grama, onde há raízes por todos os lados, entrelaçadas, uma multiplicidade de conexões em constante expansão.

3 “a crioulização é a mestiçagem acrescida de uma mais-valia que é a imprevisibilidade" (GLISSANT, 2013, p. 21).
} 
que se obstinavam há muito tempo - a crença de que a identidade de um ser só é válida e reconhecível se for exclusiva, diferente da identidade de todos os outros seres possíveis" (GLISSANT, 2005, p. 17).

O contato e mútua interferência entre os povos forçam-nos, atualmente, a rever os conceitos de cultura e de identidades em termos planetários sob o ângulo da dispersão rizomática e não mais sob a ótica estreita de uma visão de mundo com raiz única e universal. Nesse contexto, é a diversidade que passa a ser valorizada. Entretanto, como reconhecer e valorizar essa teia rizomática de relações sem desvalorizar o individual? É o que buscaremos demonstrar a seguir. Essa transposição do entendimento da identidade que passa de raiz única para uma identidade rizoma é problematizada por Glissant nos seguintes termos:

Porque de fato é disso que se trata: de uma concepção sublime e mortal que os povos da Europa e as culturas ocidentais veicularam no mundo; ou seja, toda identidade é uma identidade de raiz única e exclui o outro. Essa visão da identidade se opõe à noção hoje "real", nas culturas compósitas ${ }^{4}$, da identidade como fator e como resultado de uma crioulização, ou seja, da identidade como rizoma, da identidade não mais como raiz única, mas como raiz indo ao encontro de outras raízes. Assim que formulamos essa afirmação, os problemas se revelam inquietantes, porque, quando falamos de identidade raiz indo ao encontro de outras identidades, temos a impressão de uma ameaça de diluição: funcionamos sempre segundo o antigo modelo e, então, repito a mim mesmo, e, se eu não for mais eu mesmo, perco-me de mim! Ora, no atual panorama do mundo uma questão importante se apresenta: como ser si mesmo sem fechar-se ao outro, e como abrir-se ao outro sem perder-se a si mesmo? (GLISSANT, 2013, pp. 24-25).

\footnotetext{
${ }^{4}$ Glissant estabelece a distinção entre duas formas genéricas de culturas (2013, p. 24), formas culturais que chama de "atávicas", "cuja crioulização se deu há muito tempo"; e formas culturais chamadas de "compósitas", "que tendem a tornar-se atávicas, ou seja, tendem a reivindicar uma espécie de perduração - uma honorabilidade conferida pelo tempo, que seria necessária a toda cultura para estar segura de si e ter a audácia de afirmar-se." "Assim, as culturas atávicas tendem a crioulizar-se, isto é, a questionar ou a defender de forma frequentemente dramática - como na ex-Iugoslávia, no Líbano, etc. - o estatuto da identidade como raiz única. Porque de fato é disso que se trata: de uma concepção sublime e mortal que os povos da Europa e as culturas ocidentais veicularam no mundo; ou seja, toda identidade é uma identidade de raiz única e exclui o outro. Essa visão da identidade se opõe à noção hoje "real", nas culturas compósitas, da identidade como fator e como resultado de uma crioulização, ou seja, da identidade como rizoma, da identidade não mais como raiz única, mas como raiz indo ao encontro de outras raízes (GLISSANT, 2013, pp. 24-25).
} 


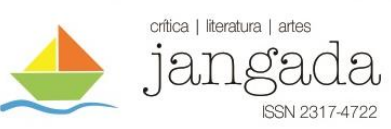

Essa indagação levantada por Glissant forma o ponto central quando se discute intercâmbios de identidades culturais sob a ótica rizomática das diversificadas possibilidades de contato entre culturas, como ocorre nos contatos proporcionados por diferentes tipos de comunicações, guerras, migrações, diásporas, colonizações e imperialismos. O conceito de processo de crioulização é apresentado por Glissant como um movimento de combinações e misturas culturais que sempre esteve presente na relação entre os povos, resultado da colocação de duas, ou mais de duas, culturas em relação, choque entre diferentes modos de ver, pensar e viver.

Essa relação entre culturas, embora possa, em tese, ocorrer sem violência, Glissant reconhece não ter encontrado exemplo desse caso (GLISSANT, 2005, p.55). Assim, na prática, o contato entre culturas é marcado por violentas lutas de diversos matizes. Como exemplo histórico de um dos maiores, se não maior, movimento global de crioulização temos o período das grandes navegações europeias, através do qual um modelo de civilização (Europeia) entra em contato, em choque, em um primeiro momento, com a civilização indígena das Américas e, posteriormente, por meio do tráfico de escravos, com as civilizações e culturas africanas. Aqui, ao invocarmos a palavra civilização, chamamos também a campo uma das questões mais polêmicas relacionadas ao conceito de identidade enfrentada pelos colonizadores das Américas: seria preciso "civilizar" aquele grupo humano que, segundo os padrões europeus, estava cerca de dez mil anos em atraso civilizatório, como observa Darcy Ribeiro:

Os grupos indígenas encontrados no litoral pelo português eram principalmente tribos de tronco tupi que, havendo se instalado uns séculos antes, ainda estavam desalojando antigos ocupantes oriundos de outras matrizes culturais. Somavam, talvez, 1 milhão de índios, divididos em dezenas de grupos tribais, cada um deles compreendendo um conglomerado de várias aldeias de trezentos a 2 mil habitantes (Fernando 1949). Não era pouca gente, porque Portugal àquela época teria a mesma população ou pouco mais.

$\mathrm{Na}$ escala da evolução cultural, os povos Tupi davam os primeiros passos da revolução agrícola, superando assim a condição paleolítica, tal como ocorrera pela primeira vez, há 10 mil anos, com os povos do velho mundo (RIBEIRO, 1995, p. 28).

Portanto, sob a ótica dos primeiros colonizadores, ainda não se reconhecia ali uma civilização como eles a concebiam. 
Posteriormente, como apontamos, o tráfico de escravos adiciona outro importante elemento cultural que passa a formar, em combinação aos elementos indígenas e europeus, a base do processo de crioulização das Américas, em especial do Brasil. Sobre o tráfico de pessoas transformadas em escravos, Glissant destaca que "o ventre do navio negreiro é o lugar e o momento em que as línguas africanas desaparecem, porque nunca se colocavam juntas no navio negreiro, nem nas plantações, pessoas que falavam a mesma língua" (2005, p. 18). Portanto, inicia-se também um processo de esfacelamento do vínculo cultural desses povos, que resultará na posterior busca desses grupos em reconstruir os rastros identitários de sua cultura no novo território, contribuindo para a criação de uma nova formação cultural.

Neste ponto, um elemento importante a ser observado para compreendermos melhor o conceito de crioulização é que, embora o processo de crioulização inicie-se com o choque entre culturas, atávicas e compósitas, a crioulização só ocorre completamente quando há igual valoração dos elementos constitutivos envolvidos, de ambas as culturas:

Porque a crioulização supõe que os elementos culturais colocados em presença uns dos outros devam ser obrigatoriamente 'equivalentes em valor para que essa crioulização se efetue realmente. Isso significa que, se nos elementos culturais colocados em relação, alguns são inferiorizados em relação a outros, a crioulização não se dá verdadeiramente. Ela se dá, mas de modo desequilibrado, que deixa a desejar, e de maneira injusta. É por essa razão que em países oriundos do processo de crioulização, como é o caso do Caribe ou do Brasil, nos quais os elementos culturais foram colocados em presença uns dos outros através do modo de povoamento representado pelo tráfico de africanos, os componentes culturais africanos e negros foram normalmente inferiorizados. A crioulização se dá, entretanto, também nesses casos, nessas condições, mas deixa um resíduo amargo, incontrolável. E quase por toda parte na Neo-America foi preciso restabelecer o equilíbrio entre os elementos colocados em presença, primeiramente através de uma revalorização da herança africana (GLISSANT, 2005, pp. 19-20).

Com o que foi até aqui colocado, frente à dualidade presente em nosso tema ao levantarmos a importância do indivíduo ao mesmo tempo que afirmamos a importância do outro presente na coletividade das línguas e das culturas, voltamos a questionar: como conciliar, portanto, a importância da existência do outro, como indivíduo ou cultura, com a afirmação da 
importância de nossa própria existência individual? Como aceitar a identidade do outro sem perder a sua própria? Como estabelecer o equilíbrio de forças culturais e políticas que possibilitaria o processo completo de crioulização em uma cultura?

Se pensarmos o mundo e a vida, em seu conjunto complexo de estruturas, sob a ótica de Nietzsche e Deleuze, como vontade de potência, ou seja, como vida que busca formas de ampliar sua potência vital buscando mais e mais vida, podemos pensar também sob esse aspecto a expansão e distribuição do homem sob a face da terra. Sabemos que são inúmeros os motivos, as linhas de forças que forçam o indivíduo, ou grupos, a deslocar-se. Não são, entretanto, as múltiplas e quase infindáveis razões desses deslocamentos que colocamos agora em foco, nem tão pouco buscamos os resultados dessas combinações. O que buscamos observar é o processo, a relação, o meio do caminho, os meios, as conexões que se estendem e conectam ampliando e reformatando o sistema mundo, permanentemente em reestruturação. Destacamos, sobretudo, as interferências provocadas que podem surgir e ecoar por todo o sistema a partir de um único ponto, um único indivíduo. E, em especial, observamos a importância do indivíduo deslocado na ampliação do imaginário global.

Imaginemos, nessa linha de pensamentos, o mundo como uma grande rede rizomática através da qual os múltiplos pontos ou elementos individuais do sistema, formados por cada indivíduo, encontram-se conectados uns aos outros. Ainda que um elemento esteja na extremidade oposta, a mais longínqua, ainda assim esse ponto estará conectado, afetando e afetado, por meio da rede, de suas tensões e afrouxamentos, por meio do transito das forças que circulam em suas fibras. Não se trata, evidentemente, de um liame físico de que tratamos aqui, são, antes, redes complexas de forças. Cada indivíduo, desde seu nascimento, está inserido e conectado a um sistema de forças local que, por sua vez, estabelece relações com todo o sistema global, formatando-se dentro de determinado diagrama de distribuição de forças.

Se imaginarmos, todo o globo como envolto por essa rede rizomática virtual de forças, poderemos imaginar cada indivíduo como um ponto nesse conjunto, ponto de intersecção, de encontro e dispersão das linhas de força da rede. O indivíduo, nesse conjunto, formaria o ponto de tangência das linhas.

Mas, enfatizamos, de que seriam formadas as linhas desta alegoria? São formadas por todo o conjunto de forças móveis que, sob determinantes do sistema, são forçadas a se estruturar e reestruturar em diagramas, em estruturas que buscam certa estabilidade homogênea. Essas forças são diversas e oriundas de relações como, por exemplo, os laços que ligam grupos políticos, sociais, econômicos, culturais, familiares, de trabalho, lazer, etc. Essas forças também 


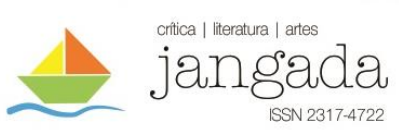

se estabelecem e tencionam de forma transnacional, como ocorre com grupos migrantes que mantem contato com seu grupo de origem; ou nas relações diplomáticas entre Estados.

Para sermos mais claros, vale outro exemplo: pensemos em um indivíduo desde seu nascimento como expressão da vontade de potência (vida buscando mais força vital), como força que busca as condições ideais para crescer, ajustar-se superando as condições, primeiramente ambientes, como as forças de seu próprio corpo, às quais ainda aprende a dominar, e as forças externas, vindas do meio, como calor e frio, barulho, dor, etc. Posteriormente tomará consciência do complexo de relações que o mundo exige, passará então a orquestrar suas forças sobre as forças diversas dos outros, físicas, psíquicas e sociais que o atravessam. Embora fatores políticos, econômicos, sociais e culturais já exerçam forte influência sobre sua existência, delimitando seu nível de acesso às experiências, o indivíduo só mais tarde se dará conta dessas variantes e do local na rede em que se encontra. O que mais vale destacar em tudo isso é a luta do indivíduo, como ponto na rede global, como vontade de potência, para ampliar sua potência dentro de um complexo diagrama sistémico de forças já estabelecido antes de sua existência.

Por outro lado, a inserção do indivíduo, seu nascimento como elemento nesse sistema, modifica o coeficiente de variáveis e relações de forças possíveis. A cada vez que nasce um homem ou mulher amplia-se a potência do imaginário humano. A ótica da vida humana ganha mais um ângulo de observação. Talvez o ângulo, a perspectiva que se mostrará decisiva, dominante no futuro para o traçado de um novo conjunto de forças.

Quem poderia negar, por exemplo, que a existência de Homero, Platão, Cristo ou Einstein tenha sido decisiva para os rumos do pensamento humano? Evidentemente suas influências, como de muitos outros homens e mulheres, tornaram-se possíveis por uma série de fatores históricos combinados e envolveu muitos outros importantes atores anônimos, determinantes para criar o campo de possibilidades e oportunidades que tornou viável deslindar novas visibilidades e enunciados em cada estrato do saber, como observava Foucault. O que nos interessa nesse conjunto, todavia, é destacar a importância do indivíduo no conjunto das relações da rede sistêmica, justificando e ampliando o pensamento que já propúnhamos desde a epígrafe.

Seguindo esse caminho de analogias que traçamos a partir da alegoria da rede-mundo, podemos ainda imaginar o adensamento de pontos na rede, representando os grandes aglomerados populacionais do mundo, e a partir daí visualizar seu deslocamento, seja em fluxos dispersos e constantes pelo mundo, por meio de viagens de turismo e negócio, ou de seu 


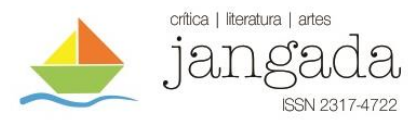

deslocamento em grandes massas, como no caso dos migrantes ou refugiados de muitos matizes, como o que vemos atualmente ocorrer no mediterrâneo, ou de episódios históricos como o tráfico de pessoas, colonizações, dentre outros.

O indivíduo, ou grupos, deslizam sobre as linhas da rede-mundo, formadas pelos caminhos que seguem os fluxos de forças, populacionais, econômicos, culturais e geotérmicos. Esse fluxo, embora varie de época a época, forma um gigantesco movimento de circulação global de pessoas e culturas pelo globo, movimento de crioulização global.

Se observarmos, complementarmente, em um geomapa a distribuição desses fluxos migratórios ao longo dos séculos XX e XXI e a distribuição dos fluxos das principais correntes térmicas pelo globo, perceberemos um equivalente pragmático dos fluxos migratórios com as correntes geotérmicas de ar e água quentes e frios que circundam o planeta. Os fluxos de correntes térmicas promovem a circulação de calor e nutrientes, funcionando como uma corrente vital que possibilita a manutenção e renovação da vida em todo o sistema global. Os fluxos migratórios, embora guardem suas peculiaridades e individualidades por vezes dramáticas, também funcionam analogamente como um grande sistema de circulação e oxigenação do sistema cultural mundial. Essa circulação migratória global, possibilitada em parte pelos avanços tecnológicos em transportes e comunicações, faz com que hoje, mais do que em qualquer outro tempo da história humana, a crioulização seja um processo global constante e, diferente do que ocorria no passado, acelerado:

No que tange ao fenômeno de crioulização, uma dimensão é importante na crioulização contemporânea: por um lado, o fato de que ela acontece de maneira fulminante e, por outro, o fato de que a consciência se dá conta de que ela está ocorrendo. Os contatos culturais sempre aconteceram, mas se estendiam ao longo de espaços temporais tão amplos, que a consciência não tomava conhecimento. Ou seja, um cidadão galo-romano do século VIII ainda havia galo-romanos nessa época - não tinha consciência de que ele era uma "mistura" de Gália e de Roma. Pensava ser para todo o sempre um cidadão romano. O resultado cultural não emergia em sua consciência por ser algo que já estava subentendido. O que há de fantástico na crioulização moderna é que, de maneira fulminante, ela penetra nas consciências. Quando vejo na televisão um tremor de terra em algum país, de maneira fulminante não apenas tomo consciência desse tremor de terra, mas sou quase que impregnado pela língua daqueles que foram atingidos, pela sua maneira de 
viver, por tudo aquilo que foi perdido, etc. Penso então imediatamente no tremor de terra que sobrevirá em meu país. Sou impregnado por tudo isso e é por isso que digo frequentemente que o escritor contemporâneo, o escritor moderno, não é monoglota, mesmo se conhece apenas uma língua, porque escreve em presença de todas as línguas do mundo (GLLISSANT, 2005, p. 29).

Assim como os fluxos de correntes térmicas, pelo mar e pelo ar, transportam nutrientes, caça, comida e vida pelo globo, tornando, inclusive, possível e mais propícia a vida em determinadas regiões em detrimento de outras regiões, também os fluxos migratórios levam vida, diversidade, crioulização para os diversos cantos da Terra.

A ideologia da raça pura, da língua ou da cultura pura e ideal revela-se cada dia mais um mito, embora defendido ainda hoje com radicalismo por grupos extremistas. Como Aponta Édouard Glissant, “toda língua originalmente é crioula” (2013, p. 31). Para Glissant não é possível pensar em termos de um sistema-mundo no qual faça sentido falar em raça pura, uma vez que todos estão em constante relação. Por isso o processo de crioulização não tem fim, é um constante recombinar. Seja em que cultura for, por mais isolada esteja, sempre haverá traços da influência de outra cultura, ainda que ancestral, ainda que tais rastros sejam ocultos, não percebidos ou rejeitados. Nesse sentido vale lembrar o exemplo dado por Edward W. Said, em Cultura e Imperialismo, quando observa que:

Londres e Paris contam com numerosas populações vindas das ex-colônias, as quais, por sua vez, guardam fortes resíduos da cultura inglesa e francesa em sua vida cotidiana. Mas isso é óbvio, vejamos, num exemplo mais complexo, as conhecidas questões da imagem da tradição ou da antiguidade clássica grega como determinante da identidade nacional. Estudos como black athena [Atenas negra], de Martin Bernal, e The invention of tradition [A invenção da tradição] , de Eric Hobsbawm e Terence Ranger, ressaltaram a extraordinária influência da preocupação atual com as imagens puras (e até expurgadas) que elaboramos a respeito de um passado privilegiado e genealogicamente útil, do qual excluímos elementos, vestígios e narrativas indesejáveis. Assim, segundo Bernal, de início sabia-se que a civilização grega tinha raízes na cultura egípcia, semita e várias outras meridionais e orientais, mas no decorrer do século XIX ela foi remodelada como uma cultura "ariana", na qual foram ocultas ou eliminadas de maneira ativa suas raízes semitas e africanas. Como 


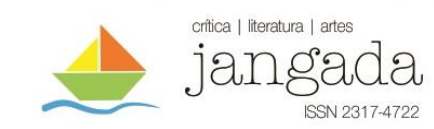

os próprios escritores gregos reconheciam abertamente o passado híbrido de sua cultura, os filólogos europeus contraíram o hábito ideológico de passar por cima dessas passagens embaraçosas, sem as comentar, em prol da pureza ática (Vale lembrar também que foi apenas no século XIX que os historiadores europeus das Cruzadas começaram a não mencionar a prática do canibalismo entre os cavaleiros francos, muito embora as crônicas dos cruzados da época se refiram sem pejo ao consumo de carne humana) (SAID, 2011, pp. 51-52).

Falar em cultura só faz sentido a partir do contato humano, da relação com o outro, da diversidade em relação. Vale lembrar, com Glissant, que estamos a considerar que "as culturas não são, mas estão dentro do processo de Relação” (2013, p. 11). E é nessa relação com o outro que o processo de recombinação cultural próprio da crioulização ocorre. Ainda que uma cultura se cristalize sob determinadas formas e regras dentro de uma sociedade, ou Estado, ainda assim estará em relação com o sistema global, ainda que prefira negar tal influência ou, como o recémnascido, ainda não se dê conta disso.

De forma análoga como as variações térmicas influem nas temporadas migratórias de aves e animais terrestres de variadas espécies, as flutuações de forças políticas, como guerras, golpes e perseguições a grupos específicos (como ocorreu com os Judeus durante a Segunda Guerra Mundial), afetam o fluxo migratório humano, forçando as forças individuais em determinada direção da rede que forma o todo-mundo, ou sistema-mundo, influenciando para a criação de novas e imprevisíveis combinações culturais e genéticas.

Como complemento ilustrativo a essa analogia proposta entre a relação dos fluxos geotérmicos e os fluxos migratórios, vale observar a imagem dos mapeamentos desses eventos individualmente e combinados:

\section{Mapa dos fluxos geotérmicos pelo globo}




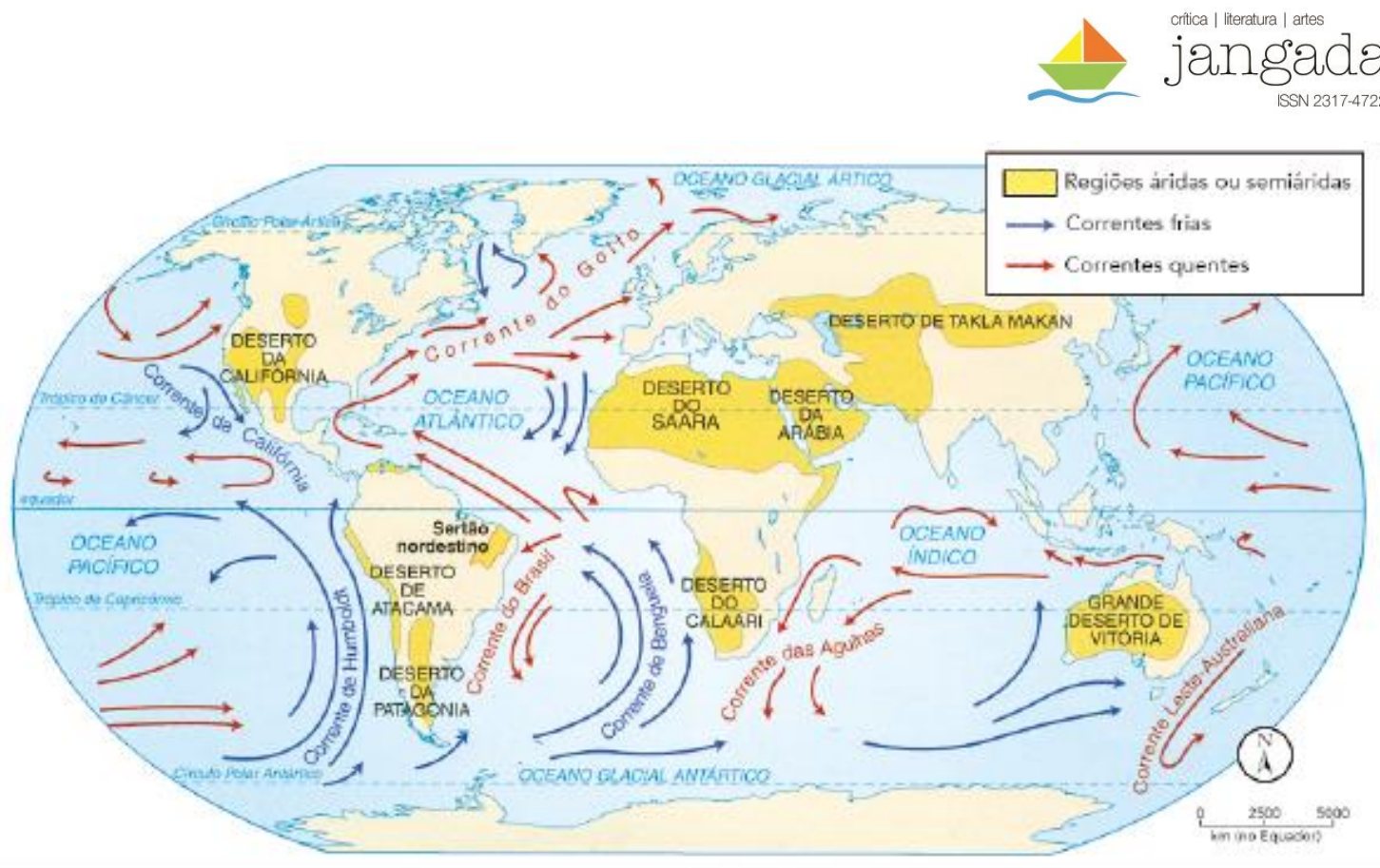

MOREIRA, J. C. Geografia geral e do Brasil. Săo Paulo: Scipione, 2010.

\section{Principais fluxos migratórios no final do século XX e início do século XXI}

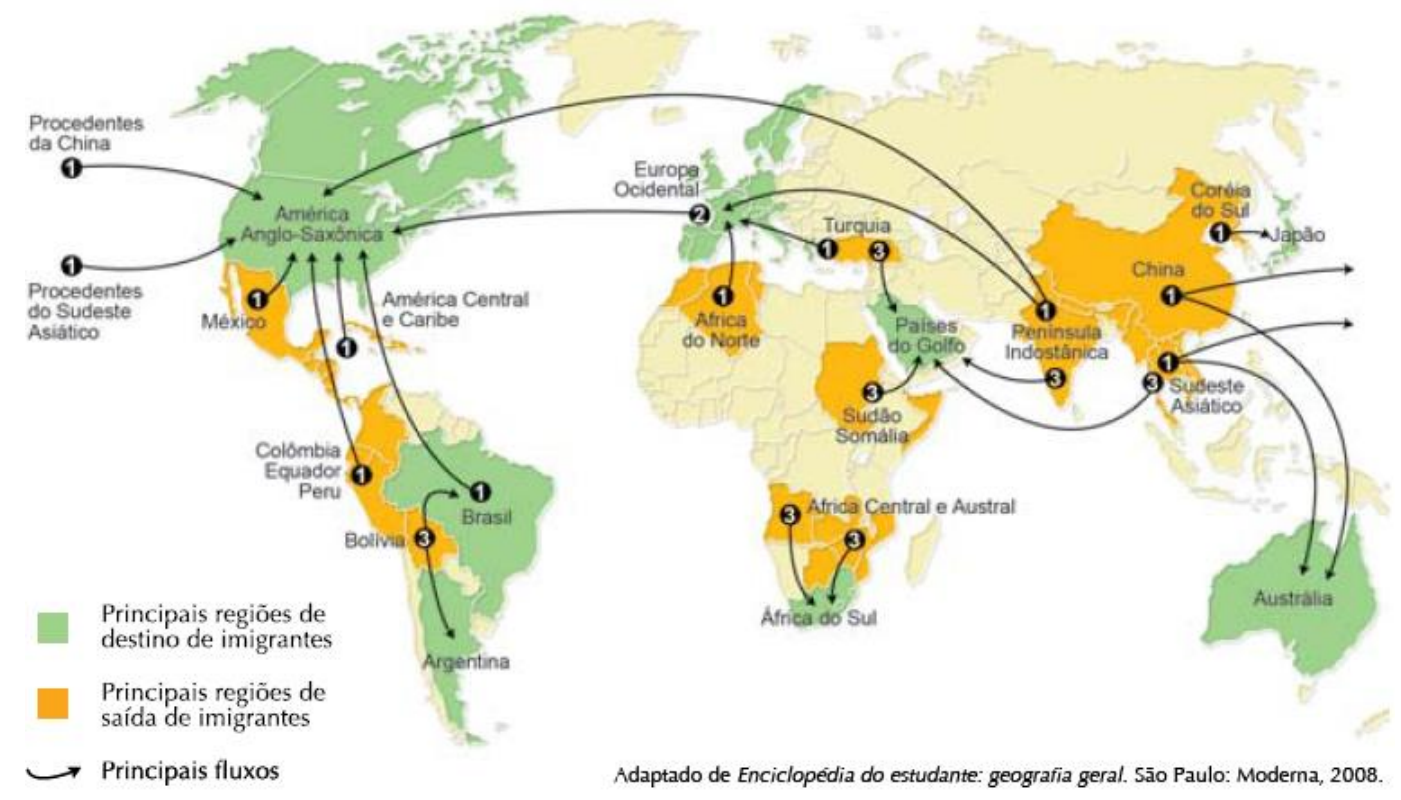

6

http://www.google.com.br/imgres?imgurl=http://www.revista.vestibular.uerj.br/lib/spaw2/uploads/images/2015/ Discursivo/Geografia/Q_6.png\&imgrefurl=http://www.revista.vestibular.uerj.br/questao/busca-questaoimprimir.php?aseq_disciplina\%3D6\&h=333\&w=597\&tbnid=dvf6E4V0zlvGyM:\&zoom=1\&docid=NMqJueeyv JbnVM\&ei=zbthVbzPIMqfggSq-oG4BA\&tbm=isch\&ved=0CE8QMygpMCk, acesso em 24/05/2015. 6 http://www.revista.vestibular.uerj.br/questao/busca-questao-imprimir.php?aseq_disciplina=6 acesso em $24 / 05 / 2015$. 


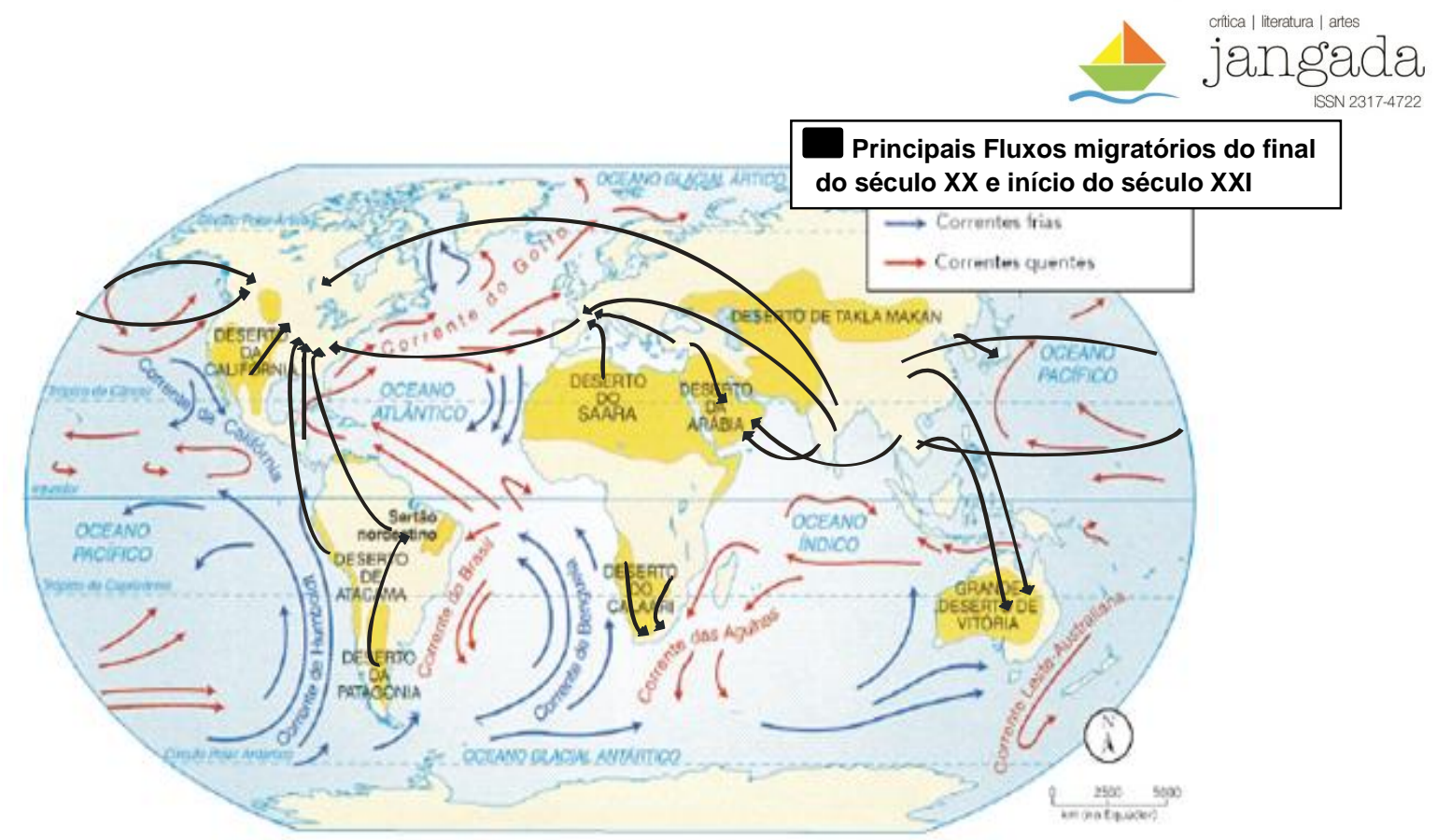

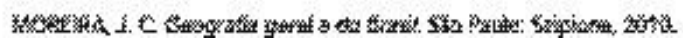

6

Pode-se confirmar, ao observar comparativamente os mapas acima, a coincidência dos fluxos migratórios deslocando-se preferencialmente em direção às áreas cercadas e irrigadas por correntes quentes, o que coincide também com a localização de algumas das nações mais poderosas, avançadas tecnologicamente, ricas, e dos maiores aglomerados populacionais do planeta.

Parece evidente que o caminho transcorrido por essas grandes correntes geotérmicas são também os locais de maior fartura e melhores condições para a vida, de forma que esse foi um dos motivos que influiu no estabelecimento de aglomerados populacionais nessas regiões desde o fim da última Era Glacial, quando as correntes térmicas globais se estabilizaram na configuração dinâmica de circulação que vemos hoje. Não estamos afirmando com isso, certamente, que apenas nessas áreas irrigadas por correntes quentes se estabeleceram civilizações, mas que essa foi a tendência natural de muitos povos devido às facilidades vitais trazidas junto às correntes térmicas que chegam dos oceanos e adentram os continentes. Vale ainda como ilustração, nesse contexto, a importância da mais conhecida entre as correntes, a chamada Corrente do Golfo. Essa corrente, que se aquece na região do Golfo do México, atravessa o oceano e é perceptível do alto por sua cor e temperatura, é o principal fluxo a levar calor e vida até a Europa.

Observar essas evidências entre os percursos das principais correntes térmicas e os percursos dos fluxos migratórios, faz-nos considerar que a relação que estabelecemos do fluxo migratório e do fluxo geotérmico, parece trazer evidências de uma macro dinâmica de deslocamento formando um adensamento e deslocamento das linhas (caminhos) de força por Jangada | nr. 9, jan/jun, 2017 | ISSN 2317-4722 - 118 | P á g in a 


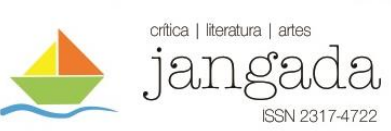

determinados trechos do sistema-mundo. Essa coincidência, como apontamos, se dá pelo fato dos países e regiões mais ricos, destino preferencial das migrações, estarem, em geral, situados ao alcance de tais correntes térmicas. Dessa forma, pode-se assim salientar este interessante ângulo de relações entre as dinâmicas globais de crioulização e a dinâmica das forças mantenedoras da vida no planeta.

Nossa rede alegórica, portanto, não se distribui de maneira linear, mas com áreas de adensamento, com maior proximidade entre os seguimentos de linhas de forças e os pontos individuais; e outros, em locais remotos, geralmente frios e desérticos, onde vemos maior distanciamento entre os pontos individuais e um menor número de rotas por onde transitam linhas de força.

Falamos, portanto, de um sistema que tende a buscar permanentemente estabelecer um utópico equilíbrio dinâmico na distribuição dessas forças. É nesse movimento de busca de ajuste, de conflitos entre culturas atávicas e compósitas, que as misturas típicas da crioulização seguem sua marcha inexorável e sem fim.

Um indivíduo sozinho já traz consigo todo um conjunto de forças moldado e formatado para interagir com seu meio de origem, seja a nível de relações sociais, econômicas, afetivas, culturais, dentre outras. Quando esse esquema individual de forças, esse diagrama (para utilizar um termo caro a Foucault e a Deleuze), é forçado a deslocar-se de sua estrutura original, todo o sistema é forçado a rearranjar-se em um novo diagrama de forças para suportar aquela nova variante movida, inserida ou retirada do sistema local.

Um exemplo individual literário que nos parece representativo em muitos aspectos é a experiência de deslocamento vivida e registrada por Villém Flusser em seu livro autobiográfico Bondelos: uma autobiografia filosófica. Nesse texto o deslocamento encontra-se mesclado ao sentimento de "sem fundamento" que nos é relatado, por meio de linguagem literária transpassada por temas e pensamentos filosóficos.

O texto começa já em 1939, quando Flusser, com dezenove anos, foge de sua cidade para não ser morto no cerco nazista. $\mathrm{O}$ autor busca por meio de sua narrativa destacar o sentimento de "sem fundamento" que a experiência do deslocamento forçado lhe impõe:

A experiência da falta de fundamento não pode ser precipitada em literatura, filosofia e arte sem ser falsificada. Pode ser apenas circunscrita em tais formas, para ser parcialmente captada. Mas é possível atestá-la de maneira direta, autobiograficamente: na esperança de que tal atestado sirva de espelho para 


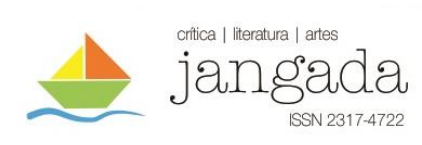

outros. A própria vida pode tornar-se laboratório para outros. É este (e não, assim espero, vaidade ou vontade de auto-afirmação) o motivo do presente livro.

Todos conhecemos o clima da falta de fundamento de experiência própria e, se o negamos, é que conseguimos reprimi-lo (vitória duvidosa). Mas há os que se encontram na falta de fundamento, por assim dizer, objetivamente, seja porque foram arrancados da realidade por forças externas, seja porque abandoaram espontaneamente uma situação aparentemente real, mas por eles diagnosticada como fantasmagoria. Os que caíram, portanto, na falta de fundamento ou a escolheram. São os tais que podem servir de laboratório para os outros. Existem mais intensamente, se "existir" for interpretado como "viver por fora". O presente livro será atestado de uma tal existência intensa. (FLUSSER, 2007, pp. 20-21).

Flusser foge de Praga para a Inglaterra, depois para o Brasil (1940), chegando ao Rio de Janeiro e seguindo para São Paulo, até 1973, migrando posteriormente para a França. Em 1991 volta a Praga, onde vem a falecer no mesmo ano.

Flusser, no Brasil, tornou-se professor e autor de diversos livros e artigos que influenciaram de maneira permanente o pensamento nacional e mundial. Como sugerimos, ao trazer a epígrafe destas reflexões, o destino ou morte de um homem influi no destino de toda humanidade. Quantos grandes gênios não revelados, quantos projetos inéditos de mundo e pensamentos se perderam nos genocídios que ocorreram e continuam a ocorrer pelo mundo? Variações em histórias individuais tem o potencial de modificar todo conjunto de histórias coletivas. É nesse sentido que se torna urgente a valorização da diversidade, da identidade rizoma, em oposição ao estabelecimento de padrões dominantes de pensamentos, como na identidade raiz única. Faz-se necessário a valorização das experiências periféricas, do contraditório, do chamado "não civilizado", do pensamento indígena tribal, dentre outros, para que não ocorra o desperdício da existência, como lembra Boaventura dos Santos ao pensar em uma teoria da Tradução e uma Sociologia da ausência:

O objetivo da sociologia das ausências é transformar objetos impossíveis em possíveis e com base neles transformar as ausências em presenças. (...) 


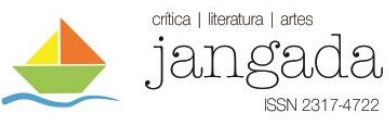

São, assim, cinco as principais formas sociais de não-existência produzidas ou legitimais pela razão metonímica: o ignorante, o residual, o inferior, o local e o improdutivo. Trata-se de formas sociais de inexistência porque as realidades que elas conformam estão apenas presentes como obstáculos em relação às realidades que contam como importantes, sejam elas realidades científicas, avançadas, superiores, globais ou produtivas. São, pois, partes desqualificadas de totalidades homogéneas que, como tal, apenas confirmam o que existe e tal como existe. São o que existe sob formas irreversivelmente desqualificadas de existir.

A produção social destas ausências resulta na subtracção do mundo e na contracção do presente e, portanto, no desperdício da existência. (SANTOS, 2002, pp. 246-249).

É a luta contra esse desperdício da existência, contra essa redução do potencial imaginário, que buscamos valorizar ao destacar o individual como elemento formador de variações de relações inseridas no sistema, portanto, responsáveis em conjunto pela riqueza da diversidade que forma o diagrama de forças global e individual. Para ampliar o suporte teórico de nosso argumento, vale lembra complementarmente a teoria do Caos. Em 1961 o cientista americano Edward Norton Lorenz (1917-2008), fundador dessa teoria, observou um efeito ao mandar acidentalmente um computador reprocessar alguns cálculos com pequenas variações, arredondando o número 0,506127 para 0,506. Tal mudança, aparentemente insignificante, resultou ao longo do tempo em imensa variação da curva do gráfico analisado. A partir dessas observações desenvolve a teoria do caos:

Formalmente, é definida como o estudo de complexos sistemas não lineares. A teoría do caos descreve o comportamento de certos sistemas - isto é, sistemas cujo estado evolui com o tempo - que podem apresentar e que são altamente sensíveis às condições iniciais (popularmente referido como o efeito borboleta). Como resultado desta sensibilidade, que se manifesta como um crescimento exponencial das pertubações nas condições iniciais, o comportamento de sistemas caóticos parece ser aleatório. Isto acontece apesar de estes sistemas serem deterministas, o que significa que seu futuro dinâmico está totalmente definido por suas condições iniciais. Este comportamente é conhecido como o caos determinista, ou simplesmente caos. 


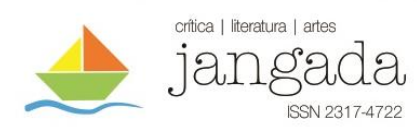

A teoría de que uma mudança ocorrida no início de um evento qualquer pode ter consequências desconhecidas no futuro. Isto é, se você realizar uma ação neste exato momento, essa terá um resultado amanhã, embora desconhecido. Lorenz descobriu que acontecimentos simples tinham um comportamento tão desordenado quanto a vida. Alguns cientistas concluíram também que a mesma imprevisibilidade aparecia em quase tudo, do número de vezes que o olho pisca até a cotação da Bolsa de Valores. Para reforçar essa teoría, na década de 1970, o matemático polonés Benoit Mandelbrot notou que as equações de Lorenz coincidiram com as que ele próprio havia feito quando desenvolveu os fractais (figuras geradas a partir de fórmulas que retratam matemáticamente a geometría da natureza, como o relevo do solo, etc). A junção do experimento de Lorenz com a matemática de Mandelbrot indica que a Teoria do Caos está na essência de tudo, dando forma ao universo.

Assim, a teoría do caos não é uma teoría da desorden, mas a busca no aparente acaso de uma ordem intrínseca determinada por leis precisas. Além do clima, outros procesos aparentemente casuais apresentam certa ordem, como por exemplo o quebrar das ondas do mar, crescimento populacional, arritmias cardíacas, flutuações do mercado financiero, etc... (MARQUEZI, 2008, p. 1).

Do mesmo modo que a variação dos números por arredondamento de algumas casas decimais pode influir drasticamente na variação da curva de um gráfico, a destruição de uma língua empobrece todas as línguas do mundo e todos os indivíduos, como sugere Glissant. Assim também como a morte de um único indivíduo pode forçar negativamente a variação das curvas do imaginário possível. A cada novo homem que nasce, mais um horizonte é somado aos muitos horizontes possíveis e imagináveis. Glissant chama de "sistema determinista errático" (2013, p. 101) a essa pluralidade de combinações de relações entre os múltiplos pontos do sistema, interinfluenciando-se e influenciando todo conjunto, rede de relações que se modifica constantemente, uma vez que novos movimentos, nascimentos e mortes alteram em contínuo o fluxo do coeficiente de forças:

Nesse sentido, há fraturas, contradições que nos introduzem imediatamente em um dos elementos essenciais da ciência do caos: a noção de sistema determinista errático. Eu não saberia "falar de ciência" com os senhores, não tenho, definitivamente, esse dom. Mas a noção de sistema determinista 


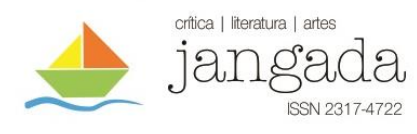

errático, que é uma das noções básicas das ciências do caos na física, é aplicável ao que chamo de caos-mundo.

A ciência do caos afirma que existem sistemas dinâmicos determinados que se tornam erráticos. Em princípio, um sistema determinista tem uma fixidez, uma "mecanicidade" e uma regularidade de funcionamento; o que a ciência do caos descobriu é que existe uma infinidade de sistemas dinâmicos determinados que se tornam erráticos; ou seja - é esta a minha interpretação a um dado momento seu sistema de valores flutua, sem que, à primeira vista, saibamos porquê. Essa é a minha interpretação. Os cientistas do caos testam essa noção de sistema determinista errático e a verificam em toda uma série de aspectos e de representações do real. (...) O que me interessa é o comportamento imprevisível dessa relação das culturas, imprevisibilidade que constitui uma das bases da ciência do caos. O comportamento imprevisível está associado a noção de sistema determinista errático. Os físicos do caos afirmam que todo sistema que possui apenas dois graus de liberdade, ou seja, duas variáveis, nunca se torna errático. Mas quando os sistemas contêm mais de duas, isto é, quando as variáveis se multiplicam e sobretudo quando se introduz a variável tempo - é por isso que começamos esta conferência abordando a questão do tempo - a imprevisibilidade se confirma (GLISSANT, 2013, p. 87).

Essas observações evidenciam a importância do indivíduo, da identidade rizomática na equação de forças que forma o todo cultural global em constante processo de reformulação e crioulização.

Para concluir, retomemos à problemática que já apresentávamos ao início de nossas reflexões sobre como conciliar a identidade individual com a identidade global sem que se perca a identidade individual. O que é preciso compreender é que estar em relação com o outro não significa abandonar sua identidade, mas perceber que nessa relação com o outro é que se formam as identidades que, por sua vez, estão em constante transformação, afetando-se mutuamente. Sobre essa questão Glissant ressalta a importância de perceber o sistema global com um "Todo-o-mundo":

(...) o problema hoje é conseguirmos mudar a própria noção de identidade, a própria profundidade da vivência que temos de nossa identidade, e concebermos que somente o imaginário do Todo-o-mundo (isto é, o fato de 
que eu possa viver em meu lugar estando em relação com a totalidade-mundo), somente esse imaginário pode nos fazer ultrapassar essas espécies de limites fundamentais que ninguém quer ultrapassar. O Todo-o-mundo é uma desmedida e se não captarmos a dimensão dessa desmedida, corremos o risco, na minha opinião - e esta é uma das bases da minha poética, do que poderíamos chamar de minha poética - de arrastar eternamente as velhas impossibilidade que sempre determinam as intolerâncias, os massacres e os genocídios (GLISSANT, 2013, p. 92).

Nessa linha, como ferramenta complementar que pode ajudar a perceber esse Todo-omundo, valorizando a diversidade como a base para a consciência de uma identidade rizoma, vale considerar a proposta de tradução expressa por Boaventura dos Santos na chamada teoria da tradução. Trata-se de um método utilizado para identificar o que é comum entre duas culturas, ela, "a teoria da tradução permite a identificação de um campo comum em uma luta indígena, uma luta feminista, uma luta ecológica etc., sem fazer desaparecer em nenhuma delas a autonomia e a diferença que as sustenta (SANTOS, 2003, p. 40). Essas estratégias, descritas por Glissant e Boaventura, são exemplos de buscas por traduzir ferramentas e métodos de pesquisas e percepção da realidade que nos permitam ampliar nossa visão a partir da reformulação de nossa concepção de identidade. Compreender a identidade como rizoma significa considerar cada ramo desse rizoma, cada indivíduo, como parte dessa grande teia identitária. Ao ampliamos nossas redes de relações elaborando concepções alegóricas, seja por meio de estudos comparados, relacionando aspectos de campos diversos do conhecimentos e discursos, tais como os estudos culturais e sociais, literários e geopolíticos, estaremos também contribuindo para a ampliação do imaginário e dessa rede rizomática de relações.

A questão conclusiva é que não se deve pensar em estagnar o irreversível e acelerado processo de crioulização global, mas, pelo contrário, reconhecendo-o, buscar alternativas para que o choque entre culturas seja valorizado como elemento de revitalização, diversificação e oxigenação, caminhando assim para a possibilidade do surgimento de processos de crioulização não violentos e completos, ou seja, com valorização igualitária dos elementos identitários envolvidos. 


\section{REFERÊNCIAS BIBLIOGRÁFICAS}

BOSI, Alfredo. Dialética da Colonização. São Paulo: Companhia das Letras, 1995.

DELEUZE, Gilles; GUATTARI, Félix. O Anti-Édipo. Tradução. Luiz B. L. Orlandi. São Paulo: editora 34, 2010.

. Mil platôs: capitalismo e esquizofrenia. Tradução Suely Rolnik. $6^{\text {a }}$ ed. São Paulo: editora 34, 2011. v. 1.

GLISSANT, Édouard. Introdução a uma Poética da Diversidade. Trad. Enilce albergaria Rocha. Juiz de Fora: Editora da UFJF, 2005.

HALL, Stuart. Da diáspora: Identidades e Mediações Culturais. Org. Liv Sovik. Belo Horizonte: Editora da UFMG, 2003.

MAZZOLENI, Gilberto. O Planeta Cultural: para Uma Antropologia Histórica. São Paulo: Edusp, 1992.

SAID, Edward. Cultura e Imperialismo. São Paulo: Companhia das Letras, 1995.

. Reflexões Sobre o Exílio e outros Ensaios. São Paulo: Companhia das Letras, 2001.

SOUSA SANTOS, Boaventura de. Reconhecer para libertar: os caminhos do multiculturalismo cultural. Rio de Janeiro: Civilização Brasileira, 2003;

Para uma sociologia das ausências e uma socióloga das emergências. In: Revista

Crítica de Ciências Sociais, 63, Outubro 2002, p. 237-280.

TODOROV, Tzvetan. A Conquista da América. A Questão do Outro. São Paulo: Martins Fontes, 1993.

\section{SITES:}

Moreira, J.C. Geografia geral e do Brasil. São Paulo: Scipione, 2010, no endereço eletrônico: >http://www.google.com.br/imgres?imgurl=http://www.revista.vestibular.uerj.br/lib/spaw2/u ploads/images/2015/Discursivo/Geografia/Q_6.png\&imgrefurl=http://www.revista.vestibular. uerj.br/questao/busca-questao-

imprimir.php?aseq_disciplina\%3D6\&h=333\&w=597\&tbnid=dvf6E4V0zlvGyM:\&zoom=1\& docid=NMqJueeyvJbnVM\&ei=zbthVbzPIMqfggSq-

oG4BA\&tbm=isch\&ved=0CE8QMygpMCk, $<$ acesso em 24/05/2015.

Universidade do Estado do Rio de Janeiro - UERJ. Revista Eletrônica do Vestibular. Departamento de Seleção Acadêmica.

http://www.revista.vestibular.uerj.br/questao/busca-questao-imprimir.php?aseq_disciplina=6 ., acesso em 24/05/2015. 